\title{
Towards Highly Accurate Spin State Energetics in First-Row Transition Metal Complexes: A Combined CASPT2/CC Approach
}

\author{
Quan Manh Phung, Milica Feldt, Jeremy N. Harvey, and Kristine Pierloot* \\ Department of Chemistry, KU Leuven, Celestijnenlaan 200F, B-3001 Leuven, Belgium \\ E-mail: kristin.pierloot@kuleuven.be
}

\begin{abstract}
In previous work on the performance of multiconfigurational second-order perturbation theory (CASPT2) in describing spin state energetics in first-row transition metal systems [J. Chem. Theory Comput. 2017, 13, 537-553], we showed that standard CASPT2 works well for valence correlation but does not describe the metal semicore (3s3p) correlation effects accurately. This failure is partially responsible for the wellknown bias towards high-spin states of CASPT2. In this paper, we expand our previous work and show that this bias could be partly removed with a combined CASPT2/CC approach: using high-quality CASPT2 with extensive correlation-consistent basis sets for valence correlation and low-cost $\operatorname{CCSD}(\mathrm{T})$ calculations with minimal basis sets for the metal semicore $(3 \mathrm{~s} 3 \mathrm{p})$ correlation effects. We demonstrate that this approach is efficient by studying the spin state energetics of a series of iron complexes modelling important intermediates in oxidative catalytic processes in chemistry and biochemistry. The average error of this approach, compared to $\operatorname{CCSD}(\mathrm{T})$ results, is estimated to be around $2 \mathrm{kcal} \mathrm{mol}^{-1}$.
\end{abstract}

${ }^{*}$ To whom correspondence should be addressed 


\section{Introduction}

The accurate description of the relative energy of different spin states in transition metal (TM) complexes, in short denoted as TM spin state energetics, is currently an important issue in computational chemistry, and is essential for the description of reactivity in bio-inorganic catalysis as well as of magnetic properties such as spin crossover. ${ }^{1-3}$ However, choosing an appropriate theoretical method that can quantitatively describe TM spin state energetics is challenging, ${ }^{4}$ as this method should combine high reliability with low computational cost. The second factor certainly plays in favor of density functional theory (DFT), which can today be applied routinely to medium-to-large-sized molecules. However, DFT is known to suffer from significant difficulties in describing TM spin state energetics, yielding results that are highly dependent on the applied exchange-correlation functional, and in particular on the contribution of Hartree-Fock (HF) exchange. ${ }^{5-9}$ On the other hand, high-quality wavefunction theory (WFT) calculations are more reliable, but these methods are computationally more demanding than DFT even for small systems, and they typically become much more time-consuming for larger molecular models. ${ }^{10-13}$ The CCSD(T) coupled cluster approach, ${ }^{14,15}$ the 'gold standard' in WFT, as well as many recently developed composite methods based on CCSD(T), have been increasingly used and excellent results were obtained in many cases. ${ }^{16-18}$ However, $\operatorname{CCSD}(\mathrm{T})$ is costly, especially for larger molecules, and is not very accurate for systems with high multireference character, with these factors significantly limiting its applicability. For large complexes or systems with high multireference character, multiconfigurational perturbation theory based on an active space reference wavefunction CASSCF/CASPT2, ${ }^{19}$ CASSCF/NEVPT2, ${ }^{20,21}$ RASSCF/RASPT2 $2{ }^{22}$ or novel methods such as density matrix renormalization group DMRG/CASPT2, ${ }^{23-29}$ DMRG/NEVPT2 20,31 are therefore often used instead, since they scale better with system size and can describe the wavefunction more accurately. With a well-chosen active space (R)CASSCF or DMRG can recover a large part of the static correlation, while the subsequent PT2 step can describe the remaining, dynamic correlation. Multiconfigurational perturbation theory CASPT2 has 
been successfully applied to study spin state energetics of various TM complexes, but it has its own problematic aspect: it is regularly found to overstabilize high-spin (HS) with respect to intermediate-spin (IS) or low-spin (LS) states (by up to $10 \mathrm{kcal} \mathrm{mol}^{-1}$ ). ${ }^{11,32-36} \mathrm{In}$ a recent study ${ }^{37}$ we have demonstrated that CASPT2 works well for valence correlation and that the bias towards HS states essentially arises from a poor perturbational treatment of the TM semi-core (3s3p) electron correlation contribution. This conclusion was drawn based on a comparison between CASPT2 and CCSD(T) results for the spin state energetics of an extensive series of TM complexes. As long as only the valence electrons are correlated, excellent correspondence (within $3 \mathrm{kcal} \mathrm{mol}^{-1}$ ) was obtained between the $\operatorname{CCSD}(\mathrm{T})$ and CASPT2 relative energies. However, CASPT2 systematically underestimates or even predicts the wrong sign for the (3s3p) correlation contribution to IS-HS and LS-HS splittings. This erratic description of (3s3p) correlation with CASPT2 is responsible for a strong overstabilization of higher with respect to lower spin states in the full CASPT2 treatment. Two other important points to note from our previous work are (a) that the alternative NEVPT2 method (based on a more sophisticated zeroth-order Hamiltonian) ${ }^{20,21}$ does not offer an improvement over CASPT2, as it systematically shows larger errors both in the valence and (3s3p) correlation, and (b) that the (3s3p) correlation contribution is systematically more accurately described even by CCSD than by CASPT2, notwithstanding that the former method, incapable of capturing the multireference effects in these TM systems, is obviously inferior in its global description of spin state energetics.

Knowing that CASPT2 works well for valence correlation but not for (3s3p) correlation, the question naturally arises whether it might be possible to split these two correlation contributions and treat them with different methods, that is (a) the contribution of all valence electrons with CASPT2, and (b) the (3s3p) correlation contribution with $\operatorname{CCSD}(\mathrm{T})$ or, if that is too costly, with CCSD. Of course, this does not reduce the computational cost with respect to a full CC calculation, unless one might consider employing more limited basis sets for the CC treatment of $(3 \mathrm{~s} 3 \mathrm{p})$ correlation than for the CASPT2 treatment of valence 
correlation. The latter possibility does not seem unrealistic, knowing that (3s3p) correlation is essentially located on the metal, and may therefore be less affected by the size of the ligand basis sets.

In this work we explore the scope of such a combined CASPT2/CC approach to study of the spin state energetics of a series of iron complexes, chosen as models for important intermediates in oxidative catalytic processes in chemistry and biochemistry. An overview of the complexes studied is provided in Figure 1. The set contains iron complexes with different ligand sizes, iron oxidation states (II-IV) and coordination numbers (4-6). All of the complexes contain (at least) four N-donors. Most of them are heme or heme-related, containing either a porphyrin ligand $(\mathrm{P})$ or two chelating amidine ligands (abbreviated as L) that were already used to mimic the full porphyrin in several previous benchmarking studies. ${ }^{18,33,34,38}$ The remaining complex, $\left[\mathrm{Fe}\left(\mathrm{NH}_{3}\right)_{5} \mathrm{O}\right]^{2+}$, is a simplified model for the iron(IV)-oxo intermediate of synthetic nonheme oxidants involved in hydrogen abstraction processes. ${ }^{39}$

The CASPT2/CC results will be compared with either the $\operatorname{CCSD}(\mathrm{T})$ results ${ }^{18,39}$ or available experimental data. We note that most of the models, except $\mathrm{FeL}_{2} \mathrm{SH}, \mathrm{FePSH}$, and $\left[\mathrm{Fe}\left(\mathrm{NH}_{3}\right)_{5} \mathrm{O}\right]^{2+}$, have low multireference character and should be well-described by $\mathrm{CCSD}(\mathrm{T})$. This conclusion was based on the fact that the CASSCF wavefunction of the models can be basically described by one leading configuration state function, as shown in our previous work. ${ }^{37}$ Furthermore, Radon ${ }^{18}$ observed a small difference between the results of CCSD(T) and a more advanced coupled-cluster method known as $\mathrm{CR}-\mathrm{CC}(2,3)$, thus validating use of the $\operatorname{CCSD}(\mathrm{T})$ results as the references. In order to assess the validity of $\operatorname{CSSD}(\mathrm{T})$ results for $\left[\mathrm{Fe}\left(\mathrm{NH}_{3}\right)_{5} \mathrm{O}\right]^{2+}, \mathrm{FeL}_{2} \mathrm{SH}$, and FePSH, one can employ the $T 1$ and $D 1$ diagnostics based on amplitudes of the singles at the CCSD level. For transition metal compounds, Jiang et al. ${ }^{40}$ proposed rough criteria to identify molecules with small static correlation, $T 1<0.05$ and $D 1<0.15$. Violating both criteria might lead to a large uncertainty for the $\operatorname{CCSD}(\mathrm{T})$ results. The $\left[\mathrm{Fe}\left(\mathrm{NH}_{3}\right)_{5} \mathrm{O}\right]^{2+}$ model, investigated by Chen et al. ${ }^{39}$ with $\mathrm{CCSD}(\mathrm{T})$, has a slightly higher multireference character due to a strongly $\mathrm{Fe}=\mathrm{O}$ covalent bond. However, the $T 1$ 
diagnostic of the CCSD calculations is small (only around 0.010-0.016 ${ }^{39}$ ), lying within the criteria of Jiang et al. ${ }^{40}$. This indicates the validity and reliability of the $\operatorname{CCSD}(\mathrm{T})$ results of $\left[\mathrm{Fe}\left(\mathrm{NH}_{3}\right)_{5} \mathrm{O}\right]^{2+}$. In $\mathrm{FeL}_{2} \mathrm{SH}$ and FePSH, as shown by Radon ${ }^{18}$, the $T 1$ and $D 1$ diagnostics are quite high $(T 1=0.031-0.044, D 1=0.150-0.265)$. Thus, the $\operatorname{CCSD}(\mathrm{T})$ results of these two models may suffer from large errors and should be regarded with caution.

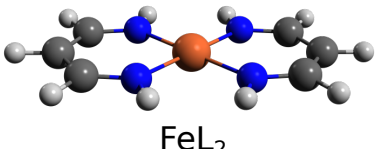

$\mathrm{FeL}_{2}$

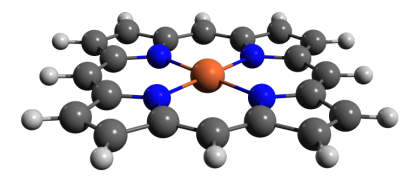

FeP

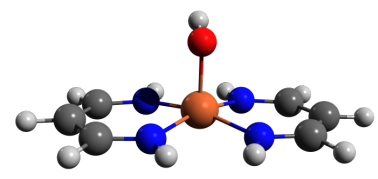

$\mathrm{FeL}_{2} \mathrm{XH}$

$\mathrm{X}=\mathrm{O}, \mathrm{S}$

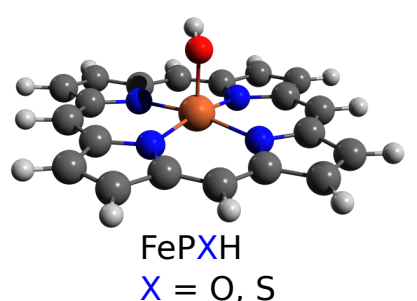

$\mathrm{X}=\mathrm{O}, \mathrm{S}$

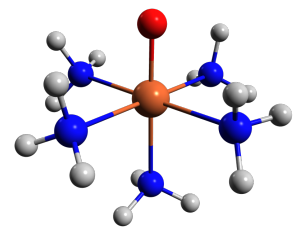

$\left[\mathrm{Fe}\left(\mathrm{NH}_{3}\right)_{5} \mathrm{O}\right]^{2+}$

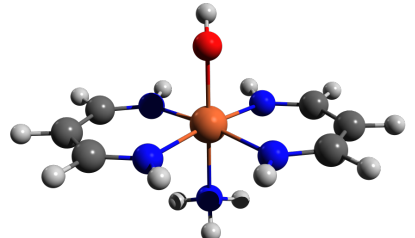

$\mathrm{FeL}_{2}\left(\mathrm{NH}_{3}\right) \mathrm{OH}$

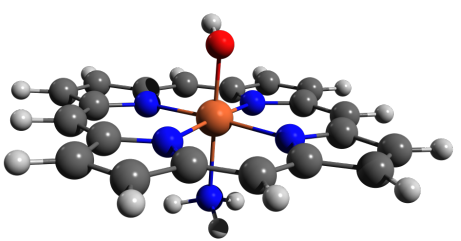

$\mathrm{FeP}\left(\mathrm{NH}_{3}\right) \mathrm{OH}$

Figure 1: Iron complexes studied in this work

\section{Computational Details}

For each of the complexes in Figure 1 the lowest state(s) of different spin multiplicities were computed. The principal electronic configurations of all considered states are provided in Table S1. For all molecules but $\left[\mathrm{Fe}\left(\mathrm{NH}_{3}\right)_{5} \mathrm{O}\right]^{2+}$ the calculations were performed on DFT geometries from previous studies ${ }^{18,37}$ (optimized separately for each spin state), and may be found in the Supporting Information of ref. 37. For $\left[\mathrm{Fe}\left(\mathrm{NH}_{3}\right)_{5} \mathrm{O}\right]^{2+}$ DFT structures for both spin states were obtained here based on optimization at the BP86/def2-TZVP level 
of theory, and making use of the TURBOmole v7.0 software. ${ }^{41}$ The resulting structures (Cartesian coordinates) are provided in the Supporting Information.

Single-point CASSCF/CASPT2 calculations were performed with MOLCAS v.8.1. ${ }^{42}$ In these calculations, Cholesky decomposition of the electron repulsion integrals with a threshold of $10^{-6}$ au was used to reduce computational times and disk storage needs. ${ }^{43}$ All CASPT2 calculations were performed with the 'standard' ionization potential electron affinity (IPEA) Hamiltonian ${ }^{44}$ of 0.25 au. An imaginary level shift of $0.1 \mathrm{au}^{45}$ was used to avoid weak intruder states and improve convergence of the perturbational treatment. The choice of the active orbitals for the CASSCF calculations was made according to the standard rules for transition metal compounds. ${ }^{11,46-48}$ The spin state energetics of all but one of the molecules (all $\mathrm{L}_{2}$ and $\mathrm{P}$ systems) was already studied with CASPT2 in our previous paper (using ANO-RCC basis sets), and a detailed description of their active spaces is given there. ${ }^{37}$ The active space of $\left[\mathrm{Fe}\left(\mathrm{NH}_{3}\right)_{5} \mathrm{O}\right]^{2+}$ was constructed to contain five Fe 3d orbitals, a 'double shell' $\mathrm{Fe} 4 \mathrm{~d}$ for each occupied $3 \mathrm{~d}$ orbital (four in the quintet, three in the triplet state), six oxygen orbitals $\mathrm{O}(2 \mathrm{p}, 3 \mathrm{p})$ and a $\sigma$-type bonding orbital on the four equatorial $\mathrm{N}$-donor atoms. This gives a total of 12 electrons in 15 (triplet) or 16 (quintet) orbitals.

Single-point CCSD(T) calculations were performed with the Molpro V.2012 ${ }^{49}$ package. All CCSD(T) calculations are (partially) spin restricted, based on restricted open-shell HF orbitals. ${ }^{14,15}$

In all CASPT2 and CC calculations scalar relativistic effects were included using a secondorder Douglas-Kroll-Hess (DKH) Hamiltonian. ${ }^{50-52}$ Spin-orbit coupling was not considered as Kepp ${ }^{53}$ recently showed that its contribution to the spin state energetics of first row TM complexes is less than $0.7 \mathrm{kcal} / \mathrm{mol}$ and typically $0.2 \mathrm{kcal} / \mathrm{mol}$.

For each molecule and spin state, i.e. for high- (HS), intermediate- (IS), and low-spin (LS), two calculations were performed, that either do or do not include the eight $\mathrm{Fe}$ (3s3p) electrons in the correlation treatment. Following the notation in our previous paper ${ }^{37}$ these calculations are indicated as $+\mathrm{sp}$ (and called full correlation) and nosp (and called valence 
correlation), respectively. Relative spin state energies, $\Delta E(+\mathrm{sp})$ or $\Delta E($ nosp $)$, were always obtained using the HS state as the reference:

$$
\Delta E(+\mathrm{sp})=E_{\mathrm{IS}, \mathrm{LS}}(+\mathrm{sp})-E_{\mathrm{HS}}(+\mathrm{sp}) ; \Delta E(n o s p)=E_{\mathrm{IS}, \mathrm{LS}}(n o s p)-E_{\mathrm{HS}}(n o s p)
$$

The $(3 \mathrm{~s} 3 \mathrm{p})$ correlation contribution for each spin state, $\Delta_{\mathrm{sp}}$, is then calculated as:

$$
\Delta_{\mathrm{sp}}=\Delta E(+\mathrm{sp})-\Delta E(\text { nosp })
$$

All calculations in this work were performed with correlation consistent (cc) basis sets, motivated by the fact that extrapolation procedures to the complete basis set (CBS) limit from the cc- basis sets have been thoroughly investigated. Different combinations of basis sets, denoted as bsM/bsL, were investigated. bsM represents the basis set on the metal and is of the type aug-cc-pwCVnZ-DK, with $n$ in the range $3-5{ }^{54}$ This basis set will be denoted awCnZ in short. For the ligands, we used a combination of aug-cc-pVnZ-DK on the heavy atoms and cc-pVnZ-DK on $\mathrm{H}$, with $n$ between 2 and $5 .{ }^{55-57}$ This combination of basis sets on the ligand atoms is denoted an $\mathrm{Z}$ in short (but note that it is not augmented on $\mathrm{H})$. Combinations of metal and ligand basis sets were chosen such that $n$ is either equal, or one or two less for $\mathrm{L}$ than for $\mathrm{M}$. This is because we expect the size of the metal basis to play the more important role for describing transitions within the metal $3 d$ shell, which are essentially (but not strictly) localized on the metal. Note that we have systematically used a metal basis set of the pwCVnZ type, designed to describe (3s3p) correlation, also in the valence calculations, where the $3 \mathrm{~s} 3 \mathrm{p}$ electrons were frozen. Because the awCnZ basis sets also include tight functions that make small but distinct contributions to the valence correlation energy, ${ }^{54}$ comparing full correlation calculations $(\Delta E(+\mathrm{sp}))$ with a awCnZ basis set with valence correlation calculations $(\Delta E$ (nosp)) using only anZ would result in an overestimation of the core correlation contribution $\left(\Delta_{\mathrm{sp}}\right)$. This was confirmed by a series of $\operatorname{CCSD}(\mathrm{T})$ calculations on $\mathrm{FeL}_{2}$, shown in Table S2. The effect of (3s3p) correlation was 
also investigated using even smaller basis sets on the ligands, that is either awCTZ/DZ or awCTZ/MIN, where DZ basis sets or MINAO basis sets (constructed from the cc-pVTZ basis sets and provided in the basis set library of MOLPRO) were used for all ligand atoms.

Extrapolation of the spin state energies to the complete basis set (CBS) limit was accomplished separately for the (HF or CASSCF) reference energy and the (PT2 or CC) correlation energy, as described in the work of Wilson et al. ${ }^{58}$ The HF and CASSCF reference energies were extrapolated using the following two-point extrapolation equation: ${ }^{59}$

$$
E_{\mathrm{ref}}(\mathrm{CBS})=\frac{e^{1.63 m_{1}} E_{\mathrm{ref}}\left(m_{2}\right)-e^{1.63 m_{2}} E_{\mathrm{ref}}\left(m_{1}\right)}{e^{1.63 m_{1}}-e^{1.63 m_{2}}}
$$

while the PT2 or CC correlation energies were extrapolated using the two-point extrapolation formula of Helgaker et al. ${ }^{60}$ :

$$
E_{\text {corr }}(\mathrm{CBS})=\frac{m_{2}^{3} E_{\text {corr }}\left(m_{2}\right)-m_{1}^{3} E_{\text {corr }}\left(m_{1}\right)}{m_{2}^{3}-m_{1}^{3}}
$$

In these equations, $m_{1}$ and $m_{2}$ denote correlation consistent basis sets of cardinal numbers $m_{1}$ and $m_{2}$. Extrapolations were only performed with respect to the Fe basis set, while keeping the ligand basis set fixed. The final total energy is the sum of the extrapolated energies:

$$
E(\mathrm{CBS})=E_{\mathrm{ref}}(\mathrm{CBS})+E_{\mathrm{corr}}(\mathrm{CBS})
$$

The extrapolated results are denoted as $\operatorname{CBS}\left[m_{1}: m_{2}\right] / m_{3}$, where $m_{1}, m_{2}$ and $m_{3}$ denote the cardinal number of the $\left[\mathrm{awCm} m_{1} \mathrm{Z}, \mathrm{awCm}_{2} \mathrm{Z}\right]$ metal and $\mathrm{am}_{3} \mathrm{Z}$ ligand basis sets, respectively. 


\section{Results and Discussion}

\subsection{Basis set dependence of valence and (3s3p) correlation in $\mathrm{FeL}_{2}$}

A first series of test calculations was performed for $\mathrm{FeL}_{2}$ making use of CASPT2 and $\operatorname{CCSD}(\mathrm{T})$ and considering the lowest states of different spin multiplicity. The results are given in Table 1. Because $\mathrm{FeL}_{2}$ is small and has $D_{2 h}$ symmetry, CASPT2 and CCSD(T) calculations with large combinations of cc basis sets are feasible. The largest combination is awC5Z/a5Z, containing 2050 basis functions. The largest combination that could be used in $\operatorname{CCSD}(\mathrm{T})$ is awC5Z/aTZ, with 860 basis functions, while the smallest combination is awCTZ/MIN, with only 187 basis functions. The purpose of these calculations is to investigate how the spin state energetics depend on the specific bsM/bsL combination. In particular, we wish to understand (a) how large should the basis sets become before we can safely extrapolate to the basis set limit, and (b) how do the results obtained with limited bsM/bsL combinations compare with the CBS results. In the following discussion, the spin state energetics obtained from a valence only treatment, $\Delta E$ (nosp) (Eq. 1), and the effect of (3s3p) correlation, $\Delta_{\mathrm{sp}}$ (Eq. 2) are considered separately.

Starting with the valence only calculations, let us first consider the largest basis set combinations to see whether the relative energies are converged with respect to the basis set size on the metal/ligand. If we compare for example three basis set combinations with the same metal basis but different ligand basis awCQZ/anZ $(n=2-4)$, we find that the $\Delta E($ nosp $)$ values increase by around $2 \mathrm{kcal} \mathrm{mol}^{-1}$ between $\mathrm{bsL}=\mathrm{aDZ}$ and aTZ, while a further extension to aQZ has a small effect, $<0.2 \mathrm{kcal} \mathrm{mol}^{-1}$. Similarly, when comparing awC5Z/anZ for $n=3-5$ the difference between $\mathrm{bsL}=\mathrm{aTZ}$ and aQZ amounts to at most $0.5 \mathrm{kcal} \mathrm{mol}^{-1}$, while the difference between aQZ and a $5 \mathrm{Z}$ is less then $0.1 \mathrm{kcal} \mathrm{mol}^{-1}$ for all three transitions. Thus we find that the relative spin state energies are close to converged with respect to bsL already at aTZ, and are strictly converged at aQZ. On the other hand (and unsurprisingly for transitions within the metal 3d shell), the size of the metal basis set 
plays the more important role: comparing awCnZ/aTZ $(n=3-5)$ or awCnZ/aQZ $(n=4-5)$ we find that the energies are lowered by around $2 \mathrm{kcal} \mathrm{mol}^{-1}$ between $\mathrm{bsM}=\mathrm{awCTZ}$ and awCQZ and further by around $1 \mathrm{kcal} \mathrm{mol}^{-1}$ between awCQZ and awC5Z. Therefore, the results are not fully converged even for bsM=awC5Z. At the top of Table 1 we have collected the CBS results based on different pairs of bsM/bsL, where bsL is kept fixed at either aQZ or aTZ and bsM with cardinal numbers 4,5 or 3,4 are used for the extrapolation. CBS[Q:5]/Q results could only be obtained from CASPT2, not $\operatorname{CCSD}(\mathrm{T})$, and these should obviously be considered the best possible CASPT2 results, while the two extrapolation schemes with aTZ ligand basis sets, [Q:5]/T and [T:Q]/T produce CBS results that slightly (by less than $\left.1 \mathrm{kcal} \mathrm{mol}{ }^{-1}\right)$ under- and overestimate $\Delta E($ nosp $)$.

Table 1: Spin state energetics and (3s3p) correlation contribution in $\mathrm{FeL}_{2}$ using different cc basis sets. Units are kcal $\mathrm{mol}^{-1}$

\begin{tabular}{|c|c|c|c|c|c|c|}
\hline & \multicolumn{2}{|c|}{$\Delta E(n o s p)$} & \multicolumn{2}{|c|}{$\Delta E(+\mathrm{sp})$} & \multicolumn{2}{|c|}{$\Delta_{\mathrm{sp}}$} \\
\hline & CASPT2 & $\operatorname{CCSD}(\mathrm{T})$ & CASPT2 & $\operatorname{CCSD}(\mathrm{T})$ & CASPT2 & $\operatorname{CCSD}(\mathrm{T})$ \\
\hline \multicolumn{7}{|c|}{$\mathrm{CBS}[\mathrm{Q}: 5] / \mathrm{Q}$} \\
\hline${ }^{3} \mathrm{~B}_{1 g}-{ }^{5} \mathrm{~A}_{g}$ & -1.83 & & -2.40 & & -0.57 & \\
\hline${ }^{3} \mathrm{~B}_{3 g}-{ }^{5} \mathrm{~A}_{g}$ & -4.34 & & -4.77 & & -0.43 & \\
\hline${ }^{1} \mathrm{~A}_{g}-{ }^{5} \mathrm{~A}_{g}$ & 32.72 & & 37.32 & & 4.60 & \\
\hline \multicolumn{7}{|c|}{ CBS[Q:5]/T } \\
\hline${ }^{3} \mathrm{~B}_{1 g}-{ }^{5} \mathrm{~A}_{g}$ & -2.67 & -3.28 & -3.22 & -6.60 & -0.55 & -3.33 \\
\hline${ }^{3} \mathrm{~B}_{3 g}-{ }^{5} \mathrm{~A}_{g}$ & -5.23 & -6.50 & -5.64 & -9.42 & -0.41 & -2.92 \\
\hline${ }^{1} \mathrm{~A}_{g}-{ }^{5} \mathrm{~A}_{g}$ & 32.04 & 30.40 & 36.65 & 28.79 & 4.61 & -1.61 \\
\hline \multicolumn{7}{|c|}{$\mathrm{CBS}[\mathrm{T}: \mathrm{Q}] / \mathrm{T}$} \\
\hline${ }^{3} \mathrm{~B}_{1 g}-{ }^{5} \mathrm{~A}_{g}$ & -1.65 & -2.38 & -2.11 & -5.56 & -0.46 & -3.18 \\
\hline${ }^{3} \mathrm{~B}_{3 g}-{ }^{5} \mathrm{~A}_{g}$ & -4.14 & -5.54 & -4.43 & -8.30 & -0.29 & -2.76 \\
\hline${ }^{1} \mathrm{~A}_{g}-{ }^{5} \mathrm{~A}_{g}$ & 33.25 & 31.45 & 38.04 & 30.07 & 4.79 & -1.38 \\
\hline \multicolumn{7}{|c|}{ awC5Z/a5Z } \\
\hline${ }^{3} \mathrm{~B}_{1 g}-{ }^{5} \mathrm{~A}_{g}$ & -1.16 & & -1.78 & & -0.62 & \\
\hline${ }^{3} \mathrm{~B}_{3 g}-{ }^{5} \mathrm{~A}_{g}$ & -3.65 & & -4.13 & & -0.48 & \\
\hline
\end{tabular}

Continued on next page 
Continuation from previous page

\begin{tabular}{|c|c|c|c|c|c|c|}
\hline & \multicolumn{2}{|c|}{$\Delta E(n o s p)$} & \multicolumn{2}{|c|}{$\Delta E(+\mathrm{sp})$} & \multicolumn{2}{|c|}{$\Delta_{\mathrm{sp}}$} \\
\hline & CASPT2 & $\operatorname{CCSD}(\mathrm{T})$ & CASPT2 & $\operatorname{CCSD}(\mathrm{T})$ & CASPT2 & $\operatorname{CCSD}(\mathrm{T})$ \\
\hline${ }^{1} \mathrm{~A}_{g}-{ }^{5} \mathrm{~A}_{g}$ & 33.58 & & 38.15 & & 4.57 & \\
\hline \multicolumn{7}{|c|}{ awC5Z/aQZ } \\
\hline${ }^{3} \mathrm{~B}_{1 g}-{ }^{5} \mathrm{~A}_{g}$ & -1.24 & & -1.83 & & -0.59 & \\
\hline${ }^{3} \mathrm{~B}_{3 g}-{ }^{5} \mathrm{~A}_{g}$ & -3.73 & & -4.16 & & -0.43 & \\
\hline${ }^{1} \mathrm{~A}_{g}-{ }^{5} \mathrm{~A}_{g}$ & 33.55 & & 38.16 & & 4.61 & \\
\hline \multicolumn{7}{|c|}{ awC5Z/aTZ } \\
\hline${ }^{3} \mathrm{~B}_{1 g}-{ }^{5} \mathrm{~A}_{g}$ & -1.73 & -2.44 & -2.28 & -5.72 & -0.55 & -3.28 \\
\hline${ }^{3} \mathrm{~B}_{3 g}-{ }^{5} \mathrm{~A}_{g}$ & -4.23 & -5.62 & -4.63 & -8.49 & -0.40 & -2.87 \\
\hline${ }^{1} \mathrm{~A}_{g}-{ }^{5} \mathrm{~A}_{g}$ & 33.20 & 31.43 & 37.84 & 29.92 & 4.64 & -1.51 \\
\hline \multicolumn{7}{|c|}{ awCQZ/aQZ } \\
\hline${ }^{3} \mathrm{~B}_{1 g}-{ }^{5} \mathrm{~A}_{g}$ & -0.65 & & -1.26 & & -0.61 & \\
\hline${ }^{3} \mathrm{~B}_{3 g}-{ }^{5} \mathrm{~A}_{g}$ & -3.11 & & -3.55 & & -0.44 & \\
\hline${ }^{1} \mathrm{~A}_{g}-{ }^{5} \mathrm{~A}_{g}$ & 34.40 & & 39.03 & & 4.63 & \\
\hline \multicolumn{7}{|c|}{ awCQZ/aTZ } \\
\hline${ }^{3} \mathrm{~B}_{1 g}-{ }^{5} \mathrm{~A}_{g}$ & -0.81 & -1.61 & -1.36 & -4.83 & -0.55 & -3.23 \\
\hline${ }^{3} \mathrm{~B}_{3 g}-{ }^{5} \mathrm{~A}_{g}$ & -3.25 & -4.75 & -3.63 & -7.56 & -0.38 & -2.81 \\
\hline${ }^{1} \mathrm{~A}_{g}-{ }^{5} \mathrm{~A}_{g}$ & 34.36 & 32.47 & 39.04 & 31.05 & 4.68 & -1.41 \\
\hline \multicolumn{7}{|c|}{ awCQZ/aDZ } \\
\hline${ }^{3} \mathrm{~B}_{1 g}-{ }^{5} \mathrm{~A}_{g}$ & -3.04 & -4.22 & -3.55 & -7.39 & -0.51 & -3.17 \\
\hline${ }^{3} \mathrm{~B}_{3 g}-{ }^{5} \mathrm{~A}_{g}$ & -5.58 & -7.49 & -6.01 & -10.25 & -0.43 & -2.76 \\
\hline${ }^{1} \mathrm{~A}_{g}-{ }^{5} \mathrm{~A}_{g}$ & 32.51 & 30.43 & 37.23 & 29.04 & 4.72 & -1.39 \\
\hline \multicolumn{7}{|c|}{ awCTZ/aTZ } \\
\hline${ }^{3} \mathrm{~B}_{1 g}-{ }^{5} \mathrm{~A}_{g}$ & 0.36 & -0.53 & -0.32 & -3.82 & -0.68 & -3.28 \\
\hline${ }^{3} \mathrm{~B}_{3 g}-{ }^{5} \mathrm{~A}_{g}$ & -2.01 & -3.65 & -2.52 & -6.53 & -0.51 & -2.87 \\
\hline${ }^{1} \mathrm{~A}_{g}-{ }^{5} \mathrm{~A}_{g}$ & 35.90 & 33.90 & 40.42 & 32.44 & 4.52 & -1.46 \\
\hline \multicolumn{7}{|c|}{ awCTZ/aDZ } \\
\hline${ }^{3} \mathrm{~B}_{1 g}-{ }^{5} \mathrm{~A}_{g}$ & -0.76 & -1.93 & -1.34 & -5.12 & -0.58 & -3.19 \\
\hline${ }^{3} \mathrm{~B}_{3 g}-{ }^{5} \mathrm{~A}_{g}$ & -3.24 & -5.07 & -3.63 & -7.84 & -0.39 & -2.77 \\
\hline${ }^{1} \mathrm{~A}_{g}-{ }^{5} \mathrm{~A}_{g}$ & 35.06 & 32.98 & 39.68 & 31.59 & 4.62 & -1.39 \\
\hline
\end{tabular}

Continued on next page 
Continuation from previous page

\begin{tabular}{|c|c|c|c|c|c|c|}
\hline & \multicolumn{2}{|c|}{$\Delta E($ nosp $)$} & \multicolumn{2}{|c|}{$\Delta E(+\mathrm{sp})$} & \multicolumn{2}{|c|}{$\Delta_{\mathrm{sp}}$} \\
\hline & CASPT2 & $\operatorname{CCSD}(\mathrm{T})$ & CASPT2 & $\operatorname{CCSD}(\mathrm{T})$ & CASPT2 & $\operatorname{CCSD}(\mathrm{T})$ \\
\hline \multicolumn{7}{|c|}{ awCTZ/DZ } \\
\hline${ }^{3} \mathrm{~B}_{1 g}-{ }^{5} \mathrm{~A}_{g}$ & -2.50 & -3.79 & -3.07 & -6.96 & -0.57 & -3.16 \\
\hline${ }^{3} \mathrm{~B}_{3 g}-{ }^{5} \mathrm{~A}_{g}$ & -4.90 & -6.78 & -5.27 & -9.53 & -0.37 & -2.75 \\
\hline${ }^{1} \mathrm{~A}_{g}-{ }^{5} \mathrm{~A}_{g}$ & 34.36 & 32.40 & 38.99 & 31.04 & 4.63 & -1.36 \\
\hline \multicolumn{7}{|c|}{ awCTZ/MIN } \\
\hline${ }^{3} \mathrm{~B}_{1 g}-{ }^{5} \mathrm{~A}_{g}$ & & -27.51 & & -30.58 & & -3.07 \\
\hline${ }^{3} \mathrm{~B}_{3 g}-{ }^{5} \mathrm{~A}_{g}$ & & -35.37 & & -37.97 & & -2.60 \\
\hline${ }^{1} \mathrm{~A}_{g}-{ }^{5} \mathrm{~A}_{g}$ & & 9.46 & & 8.18 & & -1.28 \\
\hline
\end{tabular}

More important differences in $\Delta E(n o s p)$ are observed between CASPT2 and CCSD(T), with CASPT2 predicting a higher stability for ${ }^{5} \mathrm{~A}_{g}$ with respect to the two triplet states and the ${ }^{1} \mathrm{~A}_{g}$ state. The differences between the two methods are systematic for all basis set combinations, and reach up to $1.8 \mathrm{kcal} \mathrm{mol}^{-1}$. Possible sources of error in $\operatorname{CCSD}(\mathrm{T})$ coming from multiconfigurational effects were investigated in detail in our previous study, ${ }^{37}$ and were found to be absent in all four $\mathrm{FeL}_{2}$ states. Therefore, we believe that the $\operatorname{CCSD}(\mathrm{T})$ $\Delta E$ (nosp) results in Table 1 should be considered superior to the corresponding CASPT2 results, suggesting that the latter method slightly overstabilizes ${ }^{5} \mathrm{~A}_{g}$ with respect to the states with lower spin multiplicity.

In Figure 2, the blue curve shows the average deviation (over the three spin state transitions) from CBS[Q:5]/Q of the CASPT2 $\Delta E$ (nosp) results obtained with the smaller basis set combinations. Because the dynamical correlation treatment in PT2 or CCSD(T) essentially has to overcome the strong Hartree-Fock bias towards high spin states in this (and other) transition metal complexes, one would expect the relative spin state energies to approach the basis set limit from above, that is to overestimate $\Delta E$ (nosp), with decreasing errors as the size of the basis set is increased. Most of the basis set combinations indeed 
show positive errors, and the expected trend is confirmed for increasing sizes of the metal basis set. However, somewhat surprisingly, extending the ligand basis sets (keeping bsM fixed) has the opposite effect. Thus, for each $n$, worse results are obtained with awCnZ/anZ than with awCnZ/a $(n-1) \mathrm{Z}$, with increasing differences as $n$ is decreased. Combining metal awCnZ with ligand a $(n-2) \mathrm{Z}$ gives a further decrease of the $\Delta E(n o s p)$ results. Of all finite basis set combinations, awC5Z/aTZ produces the 'best' results, with an average error of only $0.23 \mathrm{kcal} \mathrm{mol}^{-1}$ as compared to CBS[Q:5]/Q. On the other hand, awCQZ/aDZ overshoots, by producing too low $\Delta E$ (nosp) values. Such overshooting is also observed when CBS results are obtained with cardinal numbers $\left[m_{1}: m_{2}\right]=[\mathrm{Q}: 5]$ on the metal, but only aTZ on the ligands. The error is small, only $-0.8 \mathrm{kcal} \mathrm{mol}^{-1}$, but we will see further that the overshooting of the CBS[Q:5]/T results becomes more pronounced in the larger complexes considered in this work. For this reason we believe that, as a cheaper alternative to CBS[Q:5]/Q, extrapolation to CBS should preferably be done as CBS[T:Q]/T (giving a small positive error of $0.30 \mathrm{kcal} \mathrm{mol}^{-1}$ for $\mathrm{FeL}_{2}$ ) rather than $\mathrm{CBS}[\mathrm{Q}: 5] / \mathrm{T}$.

Calculations including (3s3p) correlation have also been performed with all basis sets combinations. The difference between the full and the valence correlation treatment, $\Delta_{\mathrm{sp}}$ (Eq. 2), is given in Table 1. As observed in our previous study, ${ }^{37} \operatorname{CCSD}(\mathrm{T})$ always predicts a negative $\Delta_{\mathrm{sp}}$, with values ranging between -1.4 and $-3.2 \mathrm{kcal} \mathrm{mol}^{-1}$ : introducing (3s3p) correlation assists in overcoming the HF bias towards HS states in first-row TM complexes. An important observation from our previous study (based on ANO-RCC basis sets) is also reflected in the results in Table 1: the (3s3p) correlation contribution $\Delta_{\mathrm{sp}}$ is systematically underestimated by several $\mathrm{kcal} \mathrm{mol}^{-1}$ with CASPT2, predicting values that are significantly smaller (in absolute value) for the two triplet states, and even become positive, $\sim 4.6 \mathrm{kcal} \mathrm{mol}^{-1}$, for the singlet state. Consequently, the discrepancy between the CASPT2 and $\operatorname{CCSD}(\mathrm{T})$ results increases for $\Delta E(+\mathrm{sp})$ as compared to $\Delta E(n o s p)$, with CASPT2 systematically and quite strongly (up to $8 \mathrm{kcal} \mathrm{mol}^{-1}$ ) overstabilizing HS states. A possible solution to this problem is presented in this work, i.e. we suggest to avoid calculating the 


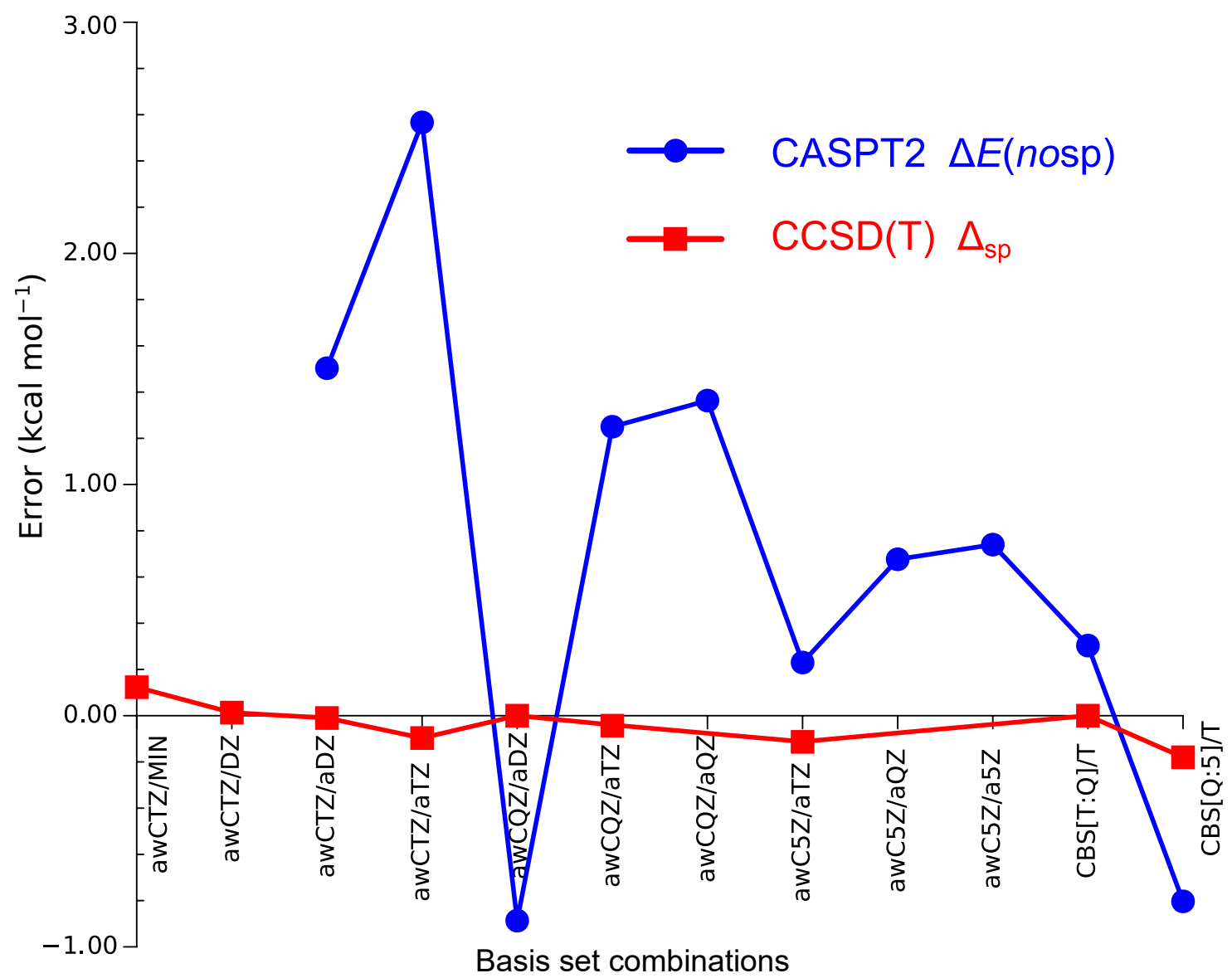

Figure 2: Basis set effect on the spin state energetics of $\mathrm{FeL}_{2}$, showing the average deviation (over the three spin state transitions) from CBS[Q:5]/Q of CASPT2 $\Delta E$ (nosp) (in blue) and from $\operatorname{CBS}[\mathrm{T}: \mathrm{Q}] / \mathrm{T}$ of $\mathrm{CCSD}(\mathrm{T}) \Delta_{\mathrm{sp}}$ (in red) 
(3s3p) correlation with CASPT2, and to use instead CCSD(T) (or CCSD, see further) to obtain $\Delta_{\mathrm{sp}}$, and to combine CASPT2 results of $\Delta E$ (nosp) with CC $\Delta_{\mathrm{sp}}$ results. The first can then be obtained in extended basis sets (extrapolated to $\mathrm{CBS}$ ), out of reach for $\operatorname{CCSD}(\mathrm{T})$. Moreover, CASPT2 will also work well for molecules that are more multiconfigurational than $\mathrm{FeL}_{2}$, and for which $\mathrm{CCSD}(\mathrm{T})$ would become less reliable (cfr next section). However, as the second step is still performed with CC, a prerequisite for this recipe to work well is that we can find relatively small basis sets that can still accurately describe (3s3p) correlation. In particular, as this correlation contribution is essentially localized on the metal we decided to check the extent to which the basis sets on the ligands could be reduced without leading to loss of accuracy for $\Delta_{\mathrm{sp}}$. Table 1 includes the results obtained with an Fe basis set of awCQZ or awCTZ quality (note that these basis sets were especially designed to treat (3s3p) correlation) but reducing the ligand basis set to DZ or even minimal (MIN). The smallest composite basis sets can no longer be trusted for the treatment of valence correlation. However, both awCTZ/DZ and awCTZ/MIN perform remarkably well for the (3s3p) correlation contribution to the spin state energetics. The red line in Figure 2 connects the deviations from CBS[T:Q]/T (which we believe is more trustworthy than CBS[Q:5]/T; see above) obtained with the different composite basis sets. As one can see, these deviations fluctuate between positive and negative, but they are always very small, below $0.1 \mathrm{kcal} \mathrm{mol}^{-1}$ in absolute value. This indicates that with a sufficiently large metal basis set, the quality of the ligand basis set has a minor impact on (3s3p) correlation. In the next Section we will show that $\operatorname{CCSD}(\mathrm{T})$ with awCTZ/MIN basis sets can be employed successfully (at a very reasonable computational cost) for the (3s3p) correlation contribution in the larger Fe complexes considered in this work (Figure 1).

\subsection{The (3s3p) correlation contribution in other Fe complexes}

Some of the other molecules in Figure 1 are too large to be treated with $\operatorname{CCSD}(\mathrm{T})$ in combination with the awCTZ/DZ basis set. Therefore, the $\operatorname{CCSD}(\mathrm{T})$ calculation of $\Delta_{\mathrm{sp}}$ 
for these complexes was only performed with the awCTZ/MIN combination. To investigate whether the MIN basis set is consistently performing well also for larger ligands, CCSD calculations were also performed with awCTZ/DZ for comparison. The results are presented in Table 2, where we have also included $\Delta_{\mathrm{sp}}$ results from our previous study on (3s3p) correlation with ANO-RCC basis sets. ${ }^{37}$

Comparing first between different basis sets, we find that the differences between the CCSD-awCTZ/MIN and CCSD-awCTZ/DZ results remain small (less than $0.2 \mathrm{kcal} \mathrm{mol}^{-1}$ ) for all complexes. This reconfirms our observation from the previous section that the quality of the ligand basis set only has a small impact on the metal (3s3p) correlation. Therefore, we conclude that awCTZ/MIN is capable of correctly describing the (3s3p) correlation contribution to the spin state energetics. We expect that the CCSD(T)-awCTZ/MIN results should be within $0.2-0.3 \mathrm{kcal} \mathrm{mol}^{-1}$ of $\operatorname{CCSD}(\mathrm{T})$-CBS values. On the other hand, the CCSD and $\operatorname{CCSD}(\mathrm{T})$ results for $\Delta_{\mathrm{sp}}$ differ more strongly between the cc- and ANO-RCC type basis sets, the latter predicting significantly more negative (3s3p) correlation contributions to the spin state energetics (up to $-1.3 \mathrm{kcal} \mathrm{mol}^{-1}$ ). It is impossible to judge from the present data which of the two basis set families is more accurate in describing (3s3p) correlation.

The results in Table 2 (see also Table S3 and Figure S1) also show a fairly good agreement between $\mathrm{CCSD}(\mathrm{T})$ and CCSD. Apart from $\left[\mathrm{Fe}\left(\mathrm{NH}_{3}\right)_{5} \mathrm{O}\right]^{2+}$ the CCSD $\Delta_{\text {sp }}$ values are always smaller (in absolute value) than the $\operatorname{CCSD}(\mathrm{T})$ results, with a maximum difference of $1.5 \mathrm{kcal} \mathrm{mol}^{-1}$. In this respect, it is important to note that the CCSD (3s3p) correlation contributions are in all cases closer to $\operatorname{CCSD}(\mathrm{T})$ than the corresponding $\mathrm{CASPT} 2$ values (see ref. 37 and the CASPT2 data in Table 3), even for molecules with covalent Fe-ligand bonds (i.e. $\mathrm{Fe}(\mathrm{III})-\mathrm{SH}, \mathrm{Fe}(\mathrm{III})-\mathrm{OH}$, and $\mathrm{Fe}(\mathrm{IV})=\mathrm{O}$ ), giving rise to (moderate) multireference character. ${ }^{37}$ This means that even for very large molecules, impossible to handle with $\operatorname{CCSD}(\mathrm{T})$ even with minimal ligand basis sets, it might still be useful to use CCSD rather than CASPT2 to treat the (3s3p) contribution to the spin state energetics.

In Table S3 and Figure S1 we have also included the MP2 results for $\Delta_{\mathrm{sp}}$. As one can 
Table 2: The (3s3p) correlation contribution to the spin state energetics of all considered Fe complexes $\left(\Delta_{\mathrm{sp}}\right.$, in $\left.\mathrm{kcal} \mathrm{mol}^{-1}\right)$

\begin{tabular}{|c|c|c|c|c|c|}
\hline & \multicolumn{2}{|c|}{ awCTZ/MIN } & \multirow{2}{*}{$\frac{\mathrm{awCTZ} / \mathrm{DZ}}{\mathrm{CCSD}}$} & \multicolumn{2}{|c|}{$\mathrm{ANO}^{-\mathrm{RCC}^{b}}$} \\
\hline & CCSD & $\operatorname{CCSD}(\mathrm{T})$ & & CCSD & $\operatorname{CCSD}(\mathrm{T})$ \\
\hline $\begin{array}{l}\mathrm{FeL}_{2} \\
{ }^{3} \mathrm{~B}_{1 g}-{ }^{5} \mathrm{~A}_{g} \\
{ }^{3} \mathrm{~B}_{3 g}-{ }^{5} \mathrm{~A}_{g} \\
{ }^{1} \mathrm{~A}_{g}-{ }^{5} \mathrm{~A}_{g} \\
\end{array}$ & $\begin{array}{l}-2.31 \\
-1.74 \\
-0.49 \\
\end{array}$ & $\begin{array}{l}-3.07 \\
-2.60 \\
-1.28 \\
\end{array}$ & $\begin{array}{l}-2.37 \\
-1.92 \\
-0.58 \\
\end{array}$ & $\begin{array}{l}-2.83 \\
-2.43 \\
-1.02 \\
\end{array}$ & $\begin{array}{l}-3.65 \\
-3.28 \\
-1.85 \\
\end{array}$ \\
\hline $\begin{array}{l}\mathrm{FeL}_{2} \mathrm{OH} \\
{ }^{4} \mathrm{~A}^{\prime \prime}-{ }^{6} \mathrm{~A}^{\prime} \\
{ }^{2} \mathrm{~A}^{\prime \prime}-{ }^{6} \mathrm{~A}^{\prime}\end{array}$ & $\begin{array}{l}-3.25 \\
-4.15\end{array}$ & $\begin{array}{l}-4.13 \\
-5.40\end{array}$ & $\begin{array}{l}-3.28 \\
-4.22\end{array}$ & $\begin{array}{l}-4.02 \\
-5.41\end{array}$ & $\begin{array}{l}-5.01 \\
-6.80\end{array}$ \\
\hline $\begin{array}{l}\mathrm{FeL}_{2}\left(\mathrm{NH}_{3}\right) \mathrm{OH} \\
{ }^{4} \mathrm{~A}^{\prime \prime}-{ }^{6} \mathrm{~A}^{\prime} \\
{ }^{2} \mathrm{~A}^{\prime \prime}-{ }^{6} \mathrm{~A}^{\prime} \\
\end{array}$ & $\begin{array}{l}-3.39 \\
-4.38 \\
\end{array}$ & $\begin{array}{l}-4.29 \\
-5.70 \\
\end{array}$ & $\begin{array}{l}-3.44 \\
-4.45 \\
\end{array}$ & $\begin{array}{l}-4.17 \\
-5.66 \\
\end{array}$ & $\begin{array}{l}-5.18 \\
-7.12 \\
\end{array}$ \\
\hline $\begin{array}{l}\mathrm{FeL}_{2} \mathrm{SH} \\
{ }^{4} \mathrm{~A}^{\prime \prime}-{ }^{6} \mathrm{~A}^{\prime} \\
{ }^{2} \mathrm{~A}^{\prime \prime}-{ }^{6} \mathrm{~A}^{\prime}\end{array}$ & $\begin{array}{l}-2.91 \\
-4.00\end{array}$ & $\begin{array}{l}-3.70 \\
-5.09\end{array}$ & $\begin{array}{l}-3.00 \\
-4.08\end{array}$ & $\begin{array}{l}-3.74 \\
-5.33\end{array}$ & $\begin{array}{l}-4.64 \\
-6.62\end{array}$ \\
\hline $\begin{array}{l}\mathrm{FeP} \\
{ }^{3} \mathrm{~A}_{2 g}-{ }^{5} \mathrm{~A}_{1 g} \\
{ }^{3} \mathrm{E}_{g}-{ }^{5} \mathrm{~A}_{1 g} \\
{ }^{1} \mathrm{~A}_{1 g}-{ }^{5} \mathrm{~A}_{1 g} \\
\end{array}$ & $\begin{array}{l}-2.36 \\
-1.95 \\
-0.39 \\
\end{array}$ & $\begin{array}{l}-3.01 \\
-2.61 \\
-1.13 \\
\end{array}$ & $\begin{array}{l}-2.37 \\
-2.01 \\
-0.44 \\
\end{array}$ & $\begin{array}{l}-2.51 \\
-2.20 \\
-0.64\end{array}$ & $\begin{array}{l}-3.16 \\
-2.83 \\
-1.35 \\
\end{array}$ \\
\hline $\begin{array}{l}\mathrm{FeP}(\mathrm{OH}) \\
{ }^{4} \mathrm{~A}^{\prime \prime}-{ }^{6} \mathrm{~A}^{\prime} \\
{ }^{2} \mathrm{~A}^{\prime \prime}-{ }^{6} \mathrm{~A}^{\prime}\end{array}$ & $\begin{array}{l}-3.29 \\
-4.27 \\
\end{array}$ & $\begin{array}{l}-4.04 \\
-5.26 \\
\end{array}$ & $\begin{array}{l}-3.34 \\
-4.38 \\
\end{array}$ & $\begin{array}{c}a \\
- \\
- \\
-\end{array}$ & $\begin{array}{c}a \\
- \\
- \\
-\end{array}$ \\
\hline $\begin{array}{l}\text { FePSH } \\
{ }^{4} \mathrm{~A}^{\prime \prime}-{ }^{6} \mathrm{~A}^{\prime} \\
{ }^{2} \mathrm{~A}^{\prime \prime}-{ }^{6} \mathrm{~A}^{\prime}\end{array}$ & $\begin{array}{l}-2.93 \\
-4.08\end{array}$ & $\begin{array}{l}-3.48 \\
-4.82\end{array}$ & $\begin{array}{l}-3.08 \\
-4.27\end{array}$ & $\begin{array}{r}a \\
- \\
-\end{array}$ & $\begin{array}{r}a \\
- \\
- \\
-\end{array}$ \\
\hline $\begin{array}{l}\mathrm{FeP}\left(\mathrm{NH}_{3}\right) \mathrm{OH} \\
{ }^{4} \mathrm{~A}^{\prime \prime}-{ }^{6} \mathrm{~A}^{\prime} \\
{ }^{2} \mathrm{~A}^{\prime \prime}-{ }^{6} \mathrm{~A}^{\prime}\end{array}$ & $\begin{array}{l}-3.25 \\
-4.21\end{array}$ & $\begin{array}{l}-4.01 \\
-5.23\end{array}$ & $\begin{array}{l}-3.28 \\
-4.30\end{array}$ & $\begin{array}{c}a \\
-a \\
-a\end{array}$ & $\begin{array}{c}a \\
-a \\
-\end{array}$ \\
\hline $\begin{array}{l}{\left[\mathrm{Fe}\left(\mathrm{NH}_{3}\right)_{5} \mathrm{O}\right]^{2+}} \\
{ }^{3} \mathrm{~A}^{\prime \prime}-{ }^{5} \mathrm{~A}^{\prime}\end{array}$ & -2.11 & -2.05 & -2.13 & - & - \\
\hline
\end{tabular}


see, this method (almost) systematically predicts too negative $\Delta_{\mathrm{sp}}$. The MP2 errors are larger (on average) and less consistent than with CCSD. The largest error $\left(4.5 \mathrm{kcal} \mathrm{mol}^{-1}\right)$ is found for the $\mathrm{Fe}(\mathrm{III})-\mathrm{SH}$ complexes. We notice that a similar behavior (too negative $\Delta_{\mathrm{sp}}$ ) was also found for the NEVPT2 method in our previous work. ${ }^{37}$

\subsection{Combining CCSD(T) (3s3p) correlation with CASPT2 va- lence correlation in TM complexes}

Table 3: Spin state energetics from CASPT2 (CBS[Q:5]/Q) combined with (3s3p) correlation contribution from $\operatorname{CCSD}(\mathrm{T})$ (awCTZ/MIN) (in kcal mol ${ }^{-1}$ )

\begin{tabular}{|c|c|c|c|c|c|c|}
\hline & & \multirow{2}{*}{$\frac{\Delta E(\text { nosp })}{\text { CASPT2 }}$} & \multicolumn{2}{|c|}{$\Delta_{\mathrm{sp}}$} & \multicolumn{2}{|c|}{$\Delta E(+\mathrm{sp})$} \\
\hline & & & CASPT2 & $\operatorname{CCSD}(\mathrm{T})$ & CASPT2 & CASPT2/CC \\
\hline \multirow[t]{3}{*}{$\mathrm{FeL}_{2}$} & ${ }^{3} \mathrm{~B}_{1 g}-{ }^{5} \mathrm{~A}_{g}$ & -1.83 & -0.57 & -3.07 & -2.40 & -4.90 \\
\hline & ${ }^{3} \mathrm{~B}_{3 g}-{ }^{5} \mathrm{~A}_{g}$ & -4.34 & -0.45 & -2.60 & -4.79 & -6.94 \\
\hline & ${ }^{1} \mathrm{~A}_{g}-{ }^{5} \mathrm{~A}_{g}$ & 32.72 & 4.60 & -1.28 & 37.32 & 31.44 \\
\hline \multirow[t]{2}{*}{$\mathrm{FeL}_{2} \mathrm{OH}$} & ${ }^{4} \mathrm{~A}^{\prime \prime}-{ }^{6} \mathrm{~A}^{\prime}$ & 8.76 & -2.22 & -4.13 & 6.54 & 4.63 \\
\hline & ${ }^{2} \mathrm{~A}^{\prime \prime}-{ }^{6} \mathrm{~A}^{\prime}$ & 12.01 & -1.95 & -5.40 & 10.07 & 6.61 \\
\hline \multirow[t]{2}{*}{$\mathrm{FeL}_{2}\left(\mathrm{NH}_{3}\right) \mathrm{OH}$} & ${ }^{4} \mathrm{~A}^{\prime \prime}-{ }^{6} \mathrm{~A}^{\prime}$ & 13.92 & -1.97 & -4.29 & 11.96 & 9.63 \\
\hline & ${ }^{2} \mathrm{~A}^{\prime \prime}-{ }^{6} \mathrm{~A}^{\prime}$ & -2.76 & -1.95 & -5.70 & -4.71 & -8.46 \\
\hline \multirow[t]{2}{*}{$\mathrm{FeL}_{2} \mathrm{SH}$} & ${ }^{4} \mathrm{~A}^{\prime \prime}-{ }^{6} \mathrm{~A}^{\prime}$ & 1.84 & -1.74 & -3.70 & 0.10 & -1.86 \\
\hline & ${ }^{2} \mathrm{~A}^{\prime \prime}-{ }^{6} \mathrm{~A}^{\prime}$ & -6.41 & -2.95 & -5.09 & -9.36 & -11.50 \\
\hline \multirow[t]{3}{*}{$\mathrm{FeP}$} & ${ }^{3} \mathrm{~A}_{2 g}-{ }^{5} \mathrm{~A}_{1 g}$ & 2.86 & 0.39 & -3.01 & 3.25 & -0.15 \\
\hline & ${ }^{3} \mathrm{E}_{g}-{ }^{5} \mathrm{~A}_{1 g}$ & 4.35 & 0.73 & -2.61 & 5.08 & 1.74 \\
\hline & ${ }^{1} \mathrm{~A}_{g}-{ }^{5} \mathrm{~A}_{1 g}$ & 32.73 & 4.45 & -1.13 & 37.18 & 31.60 \\
\hline \multirow[t]{2}{*}{$\mathrm{FePOH}$} & ${ }^{4} \mathrm{~A}^{\prime \prime}-{ }^{6} \mathrm{~A}^{\prime}$ & 13.71 & -1.57 & -4.04 & 12.14 & 9.67 \\
\hline & ${ }^{2} \mathrm{~A}^{\prime \prime}-{ }^{6} \mathrm{~A}^{\prime}$ & 19.35 & -0.91 & -5.26 & 18.45 & 14.09 \\
\hline \multirow[t]{2}{*}{$\mathrm{FeP}\left(\mathrm{NH}_{3}\right) \mathrm{OH}$} & ${ }^{4} \mathrm{~A}^{\prime \prime}-{ }^{6} \mathrm{~A}^{\prime}$ & 15.52 & -1.08 & -4.01 & 14.44 & 11.51 \\
\hline & ${ }^{2} \mathrm{~A}^{\prime \prime}-{ }^{6} \mathrm{~A}^{\prime}$ & 1.19 & -0.48 & -5.23 & 0.72 & -4.04 \\
\hline \multirow[t]{2}{*}{ FePSH } & ${ }^{4} \mathrm{~A}^{\prime \prime}-{ }^{6} \mathrm{~A}^{\prime}$ & 7.37 & -1.10 & -3.48 & 6.27 & 3.89 \\
\hline & ${ }^{2} \mathrm{~A}^{\prime \prime}-{ }^{6} \mathrm{~A}^{\prime}$ & 3.66 & -1.87 & -4.82 & 1.79 & -1.16 \\
\hline$\left[\mathrm{Fe}\left(\mathrm{NH}_{3}\right)_{5} \mathrm{O}\right]^{2+}$ & ${ }^{3} \mathrm{~A}^{\prime \prime}-{ }^{5} \mathrm{~A}^{\prime}$ & 1.73 & 0.73 & -2.05 & 2.46 & -0.32 \\
\hline
\end{tabular}

For all complexes in Figure 1 a series of CASPT2 calculations was performed on the lowest 


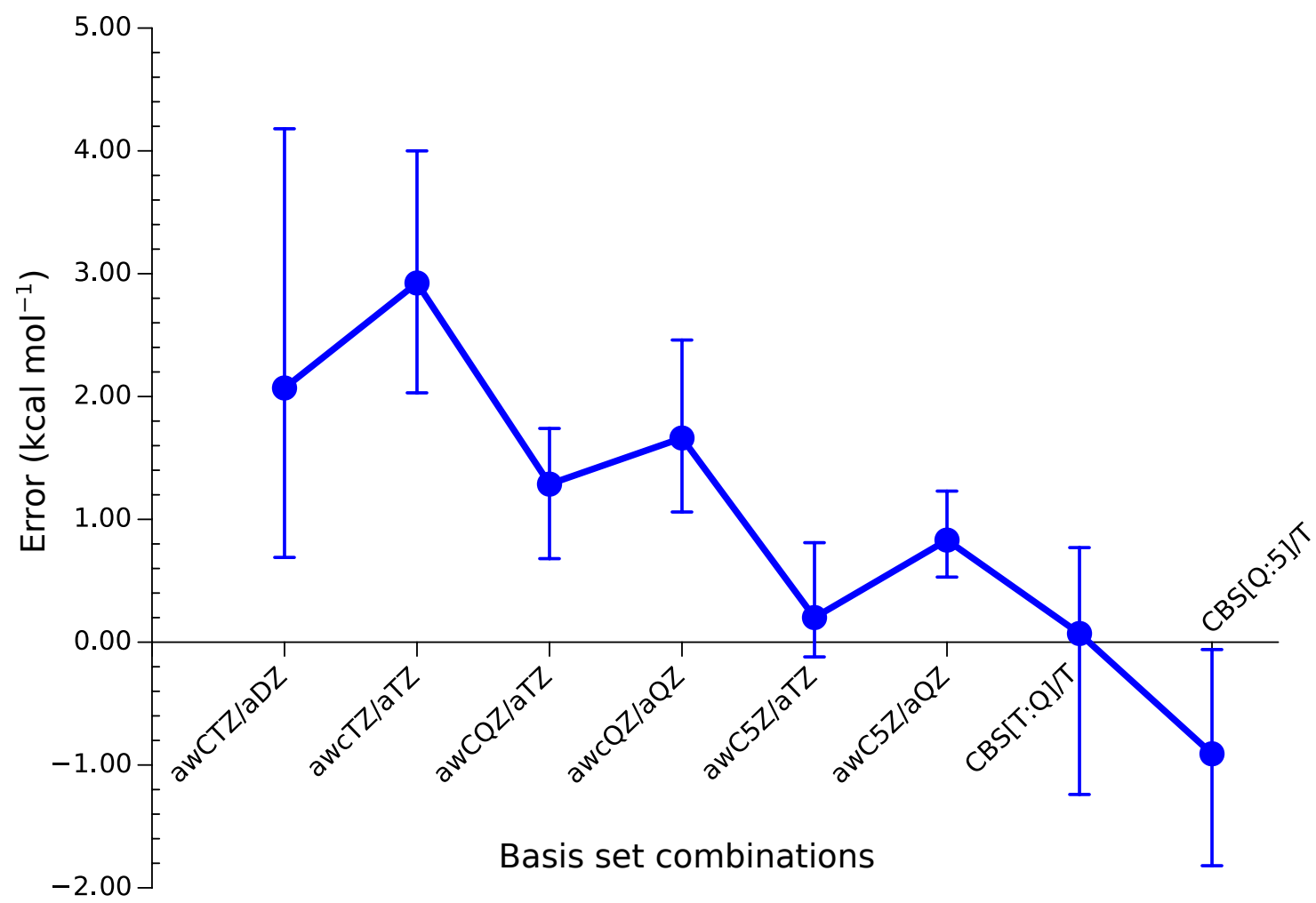

Figure 3: Basis set effect on the spin state energetics: Average and range of deviations from CBS[Q:5]/Q of the CASPT2 $\Delta E$ (nosp) results obtained with different basis set combinations

states of different spins. The principal configuration of each state can be found in Table S1. Different bsM/bsL combinations were employed, the largest combination being awC5Z/aQZ. The results of these calculations are provided in Tables S4-S8. Here, we only include the CBS[Q:5]/Q results (Table 3). In Figure 3 we present the average and range of deviations with respect to $\mathrm{CBS}[\mathrm{Q}: 5] / \mathrm{Q}$ of the relative spin state energies $\Delta E$ (nosp) obtained with different bsM/bsL combinations (see also Table S9). The evolution of the spin state energetics with basis set size follows the same trends as observed for $\mathrm{FeL}_{2}$, that is: (a) a decreasing $\Delta E$ (nosp) (and error) with an increasing bsM cardinal number; (b) an increasing $\Delta E$ (nosp) (and error) with an increasing bsL cardinal number (at fixed bsM). CBS results were obtained using three extrapolation schemes, $[\mathrm{T}: \mathrm{Q}] / \mathrm{T},[\mathrm{Q}: 5] / \mathrm{T}$, and $[\mathrm{Q}: 5] / \mathrm{Q}$. The CBS[T:Q]/T results are on average very close to CBS[Q:5]/Q, with deviations ranging between -1.2 and $0.8 \mathrm{kcal} \mathrm{mol}^{-1}$. On the other hand, the $[\mathrm{Q}: 5] / \mathrm{T}$ extrapolation produces CBS results that systematically underestimate $\Delta E$ (nosp), with errors between -0.1 and $-1.8 \mathrm{kcal} \mathrm{mol}^{-1}$. Also 
noteworthy is the excellent behavior of the awC5Z/aTZ basis set in predicting $\Delta E$ (nosp), with an average deviation from CBS[Q:5]/Q of only $0.20 \mathrm{kcal} \mathrm{mol}^{-1}$ (the mean absolute deviation is $0.24 \mathrm{kcal} \mathrm{mol}^{-1}$ ), and a maximum deviation of only $0.81 \mathrm{kcal} \mathrm{mol}^{-1}$.

The $\Delta E$ (nosp) results in Table 3 can directly be compared to our previous study, ${ }^{37}$ reporting (for all molecules except $\left.\left[\mathrm{Fe}\left(\mathrm{NH}_{3}\right)_{5} \mathrm{O}\right]^{2+}\right) \Delta E$ (nosp) data obtained with CASPT2 using exactly the same procedure (structure and active space) but with ANO-RCC rather than CC basis sets. Even though a quite extended ANO contraction scheme was used ([7s6p5d3f2g1h] for $\mathrm{Fe},[4 \mathrm{~s} 3 \mathrm{p} 2 \mathrm{~d} 1 \mathrm{f}]$ for $\mathrm{C}, \mathrm{N}, \mathrm{O},[5 \mathrm{~s} 4 \mathrm{p} 3 \mathrm{~d} 2 \mathrm{f}]$ for $\mathrm{S},[3 \mathrm{~s} 1 \mathrm{p}]$ for $\mathrm{H})$, systematically higher values of $\Delta E$ (nosp) were obtained than the CBS[Q:5]/Q results in Table 3 , by $2.2-2.7 \mathrm{kcal} \mathrm{mol}^{-1}$ for transitions involving a single spin flip, and $3.3-3.9 \mathrm{kcal} \mathrm{mol}^{-1}$ for double spin flip transitions. This points to basis set limitations in the ANO-RCC contraction scheme as a partial source for the systematic overstabilization of high spin states by CASPT2 observed in previous studies on spin state energetics in heme and heme-related systems. ${ }^{11,32-34,37,61}$

The CASPT2 results for $\Delta_{\mathrm{sp}}$ and $\Delta E(+\mathrm{sp})$ in Table 3 were obtained with CBS[Q:5]/Q. On the other hand, the $\operatorname{CCSD}(\mathrm{T}) \Delta_{\text {sp }}$ values were obtained with awCTZ/MIN basis sets (see also Table 2) and were added to CASPT2 $\Delta E($ nosp) to obtain the $\Delta E(+\mathrm{sp})$ results denoted as CASPT2/CC. The CASPT2/CC results are systematically lower by $2-6 \mathrm{kcal} \mathrm{mol}^{-1}$ than the original full CASPT2 results, the difference reflecting the CASPT2 inadequacy of treating (3s3p) correlation, with CASPT2 $\Delta_{\mathrm{sp}}$ values that are either negative but too small (in absolute value) or even have the wrong sign. It is noteworthy that both approaches predict a different ground state spin multiplicity for four of the considered molecules, $\mathrm{FeP}, \mathrm{FeP}\left(\mathrm{NH}_{3}\right) \mathrm{OH}$, FePSH and $\left[\mathrm{Fe}\left(\mathrm{NH}_{3}\right)_{5} \mathrm{O}\right]^{2+}$ : HS in all cases with CASPT2, but LS with CASPT2/CC for $\mathrm{FeP}\left(\mathrm{NH}_{3}\right) \mathrm{OH}$ and $\mathrm{FePSH}$ and IS for $\mathrm{FeP}$ and $\left[\mathrm{Fe}\left(\mathrm{NH}_{3}\right)_{5} \mathrm{O}\right]^{2+}$.

Experimentally, the ground state of four-coordinated ferrous porphyrins is intermediate spin. ${ }^{62-64}$ Previous CASPT2 calculations (using ANO-RCC basis sets) failed to reproduce this, predicting instead ${ }^{5} \mathrm{~A}_{1 g}$ as the ground state, with ${ }^{3} \mathrm{~A}_{2 g}$ several kcal mol ${ }^{-1}$ higher in energy. ${ }^{11,32,37,61}$ So far, the best computational results with WFT methods for FeP were 
obtained with $\operatorname{CCSD}(\mathrm{T})$-CBS by Radon. ${ }^{18}$ The reported ground state is ${ }^{3} \mathrm{~A}_{2 g}$, with ${ }^{3} \mathrm{E}_{g}$ at $1.7 \mathrm{kcal} \mathrm{mol}{ }^{-1},{ }^{5} \mathrm{~A}_{1 g}$ at $2.3 \mathrm{kcal} \mathrm{mol}{ }^{-1}$, and ${ }^{1} \mathrm{~A}_{1 g}$ at $32.2 \mathrm{kcal} \mathrm{mol}^{-1}$. Our CASPT2/CC results are in good agreement with the $\operatorname{CCSD}(\mathrm{T})$ data within $\sim 2 \mathrm{kcal} \mathrm{mol}^{-1}$. CASPT2/CC predicts three close-lying states: the ground state ${ }^{3} \mathrm{~A}_{2 g}$ and two low-lying excited states ${ }^{3} \mathrm{E}_{g}\left(1.89 \mathrm{kcal} \mathrm{mol}^{-1}\right)$ and ${ }^{5} \mathrm{~A}_{1 g}\left(0.15 \mathrm{kcal} \mathrm{mol}^{-1}\right)$. It is noteworthy that a CASPT2 study including spin orbit coupling also indicated that the high ground state magnetic moment of ferrous porphyrins $\left(4.4-4.7 \mu_{\mathrm{B}}\right)$ should be explained by mixing of both a low-lying ${ }^{3} \mathrm{E}_{g}$ and ${ }^{5} \mathrm{~A}_{1 g}$ into the ${ }^{3} \mathrm{~A}_{2 g}$ ground state wave function. ${ }^{61}$

FePSH is a simplified model of the pentacoordinate ferric state of the active site of the P450 enzyme, showing thermal equilibrium between the close lying $(S=1 / 2)$ and $(S=5 / 2)$ states, in which the $(\mathrm{S}=3 / 2)$ state does not participate. ${ }^{65}$ This translates in an experimental state ordering $(\mathrm{S}=1 / 2) \leq(\mathrm{S}=5 / 2)<(\mathrm{S}=3 / 2)$ in FePSH. Reproducing this ordering, especially the small difference between the doublet and sextet states, is a challenge for both CASPT2 and CCSD(T). Previous calculations employing CASPT2 ${ }^{33,37}$ (with ANO-RCC basis sets) all placed the ${ }^{6} \mathrm{~A}^{\prime}$ state below ${ }^{2} \mathrm{~A}^{\prime \prime}$ by around $4 \mathrm{kcal} \mathrm{mol}^{-1}$. Similarly, Radon ${ }^{18}$ making use of an extrapolation procedure based on $\operatorname{CCSD}(\mathrm{T})$ and DFT calculations (with a range of functionals) also predicted that the ${ }^{6} \mathrm{~A}^{\prime}$ state is lower than ${ }^{2} \mathrm{~A}^{\prime \prime}$ by $\sim 2 \mathrm{kcal} \mathrm{mol}^{-1}$. Our CASPT2/CC results agree quite well with the $\operatorname{CCSD}(\mathrm{T})$ data of both $\mathrm{FeL}_{2} \mathrm{SH}$ and FePSH within $3 \mathrm{kcal} \mathrm{mol}^{-1} \cdot{ }^{18}$ However, such $\sim 3 \mathrm{kcal} \mathrm{mol}^{-1}$ difference is large enough to alter the prediction of the ground state, ${ }^{2} \mathrm{~A}^{\prime \prime}$ is $\sim 1 \mathrm{kcal} \mathrm{mol}^{-1}$ lower than the ${ }^{6} \mathrm{~A}^{\prime}$ state at the CASPT2/CC level. As to our knowledge, this is the first time the state ordering $(\mathrm{S}=1 / 2) \leq$ $(\mathrm{S}=5 / 2)$ in FePSH is produced by a WFT calculation.

Also for the six-coordinated $\mathrm{FeP}\left(\mathrm{NH}_{3}\right) \mathrm{OH}$, CASPT2/CC predicts a ${ }^{2} \mathrm{~A}^{\prime \prime}$ ground state with a low-lying ${ }^{6} \mathrm{~A}^{\prime}$ and higher-lying ${ }^{4} \mathrm{~A}^{\prime \prime}$, while regular CASPT2 reverses the order of ${ }^{2} \mathrm{~A}^{\prime \prime}$ and ${ }^{6} \mathrm{~A}^{\prime}$. This molecule might be considered as a model for an $\mathrm{Fe}(\mathrm{III})-\mathrm{OH}$ ferric group in a histidine coordinated heme in peroxidase, which were experimentally characterized as LS possibly in thermal equilibrium with higher-lying IS and HS states. ${ }^{66,67}$ 
Finally, $\left[\mathrm{Fe}\left(\mathrm{NH}_{3}\right)_{5} \mathrm{O}\right]^{2+}$ is a simple model for hexacoordinated nonheme iron(IV)-oxo oxidants with four equatorial nitrogen donors. Such complexes are expected to have a triplet ground state with a low-lying quintet, and this was also confirmed in a previous CCSD(T) calculation, making use of def2-TZVPP basis sets for $\mathrm{Fe}=\mathrm{O}$, combined with def2-SVP on the $\mathrm{NH}_{3}$ ligands. ${ }^{39}$ With $\operatorname{CCSD}(\mathrm{T})$, the ${ }^{5} \mathrm{~A}^{\prime}$ state was found $1.3 \mathrm{kcal} \mathrm{mol}^{-1}$ higher in energy than ${ }^{3} \mathrm{~A}^{\prime}$. With CASPT2/CC this is $0.3 \mathrm{kcal} \mathrm{mol}^{-1}$, in much closer agreement with $\operatorname{CCSD}(\mathrm{T})$ than the original CASPT2 calculation, which erroneously places ${ }^{5} \mathrm{~A}^{\prime} 2.5 \mathrm{kcal} \mathrm{mol}{ }^{-1}$ below ${ }^{3} \mathrm{~A}^{\prime \prime}$.

Overall, it should be clear that the proposed CASPT2/CC combined approach offers a distinct improvement over pure CASPT2 for the prediction of spin state energetics in TM complexes. Still, the data in Table 3 also seem to indicate that, at least for the considered iron complexes, the original CASPT2 bias towards HS states is not completely lifted in CASPT2/CC. These data only include the electronic energy, not the zero-point vibrational energy (ZPVE) contribution. The latter would undoubtedly favor the HS spin state, because here (as opposed to the LS and IS states) the $\sigma$-antibonding Fe $3 \mathrm{~d}_{x^{2}-y^{2}}$ orbital is occupied, giving rise to weaker $\mathrm{Fe}-\mathrm{N}$ bonds in the $x y$ plane. Based on previous calculations, the estimated benefit for the HS state coming from the ZPVE should be around 1.5-2.5 kcal mol ${ }^{-1}{ }^{32}$ This would bring back the HS state as the lowest energy state in FeP, FePSH, and $\left[\mathrm{Fe}\left(\mathrm{NH}_{3}\right)_{5} \mathrm{O}\right]^{2+}$. This fact, together with the earlier mentioned discrepancies between the CASPT2 and $\operatorname{CCSD}(\mathrm{T})$ results in the four-coordinated $\mathrm{FeL}_{2}$ and $\mathrm{FeP}$ (Table 1 and ref. 18,37), leads us to conclude that the CASPT2/CC results in Table 3 still slightly favor the HS states, with a remaining error of $\sim 2 \mathrm{kcal} \mathrm{mol}^{-1}$.

\section{Conclusion}

The accurate calculation of spin state energetics in transition metal complexes remains a major computational challenge. We have demonstrated that the treatment of valence corre- 
lation requires very extensive correlation-consistent basis sets, prohibiting the use of conventional $\operatorname{CCSD}(\mathrm{T})$ for this purpose. The computational cost can be drastically reduced using CASPT2, while maintaining an accuracy that is close (to within $2 \mathrm{kcal} \mathrm{mol}^{-1}$ ) to $\mathrm{CCSD}(\mathrm{T})$. On the other hand, the present study confirms our previous finding that CASPT2 does not provide an accurate description of the metal (3s3p) correlation contribution to the relative spin state energies. ${ }^{37}$ In this work we have proposed an efficient alternative strategy to estimate $(3 \mathrm{~s} 3 \mathrm{p})$ correlation based on using the $\mathrm{CCSD}(\mathrm{T})$ coupled-cluster approach with a bespoke basis set, including an extensive metal awCTZ basis set and a minimal basis set on all ligand atoms. Test calculations on $\mathrm{FeL}_{2}$ indicated that the results for $\Delta_{\mathrm{sp}}$ with this basis set combination are accurate to within $0.5 \mathrm{kcal} \mathrm{mol}^{-1}$. Thus it becomes feasible to obtain an accurate estimate of (3s3p) correlation for large molecules (50-80 atoms) with moderate multireference character. For even larger molecules we propose to replace CCSD(T) by CCSD which, although less accurate than $\operatorname{CCSD}(\mathrm{T})$, is still significantly more accurate than CASPT2 in treating (3s3p) correlation. The combination of CASPT2 (CBS[Q:5]/Q) for valence correlation with $\operatorname{CCSD}(\mathrm{T})$ (awCTZ/MIN) for $(3 \mathrm{~s} 3 \mathrm{p})$ correlation, denoted as CASPT2/CC, was successfully applied to a series of iron complexes modelling important intermediates in oxidative catalytic processes in chemistry and biochemistry, and it was shown that this method can to a great extent get rid of the systematic bias towards high-spin states observed in many previous CASPT2 studies on the spin state energetics of these and other transition metal complexes. It is also important to realize that the use of more limited basis sets is also partly responsible for this bias, eg both the ANO-RCC basis sets (used in our previous work) and the TZP allover combination awCTZ/aTZ (popular in the literature) come short in the description of the valence correlation description, giving (positive) errors of $2-4 \mathrm{kcal} / \mathrm{mol}$ in $\Delta E($ nosp$)$. Finally, we note that CASPT2/CC is not a general approach to study all TM systems. For instance, $\operatorname{CCSD}(\mathrm{T})$ is still the method of choice to study small TM complexes with small to medium multireference character. In molecules with strongly multireference character, ROHF-CCSD(T) might fail, thus CASPT2/CC is less reliable. 


\section{Supporting Information Available}

Principal electronic configuration of the molecular states. $\operatorname{CCSD}(\mathrm{T})$ spin state energetics and $(3 \mathrm{~s} 3 \mathrm{p})$ correlation contribution in $\mathrm{FeL}_{2}$, using different basis set combinations. MP2 and $\operatorname{CCSD}(\mathrm{T})(3 \mathrm{~s} 3 \mathrm{p})$ correlation of other Fe complexes, using awCTZ/MIN. CASPT2 spin state energetics and (3s3p) correlation contribution of all complexes, using different basis set

combinations. Cartesian coordinates of $\left[\mathrm{Fe}\left(\mathrm{NH}_{3}\right)_{5} \mathrm{O}\right]^{2+}$. This material is available free of charge via the Internet at http://pubs . acs .org/.

\section{Acknowledgement}

This investigation has been supported by grants from the Flemish Science Foundation (FWO). QMP thanks funding from KU Leuven Postdoctoral mandates (PDM/16/112). JNH, KP and MF thank KU Leuven for funding through grant \#C14/15/052. The computational resources and services used in this work were provided by the VSC (Flemish Supercomputer Center), funded by the Hercules Foundation and the Flemish Governmentdepartment EWI. The COST Action ECOSTBio CM1305 from the European Union is also acknowledged. 


\section{References}

(1) Shaik, S.; Kumar, D.; de Visser, S. P.; Altun, A.; Thiel, W. Chem. Rev. 2005, 105, $2279-2328$.

(2) Shaik, S.; Chen, H.; Janardanan, D. Nat. Chem. 2011, 3, 19-27.

(3) Costas, M.; Harvey, J. N. Nat. Chem. 2013, 5, 7-9.

(4) Ashley, D. C.; Jakubikova, E. Coord. Chem. Rev. 2017, 337, 97-111.

(5) Ghosh, A. J. Biol. Inorg. Chem. 2006, 11, 712-724.

(6) Harvey, J. N. Principles and Applications of Density Functional Theory in Inorganic Chemistry I; Springer, 2004; pp 151-184.

(7) Swart, M. Int. J. Quantum Chem. 2013, 113, 2-7.

(8) Radoń, M. Phys. Chem. Chem. Phys. 2014, 16, 14479-14488.

(9) Swart, M.; Gruden, M. Acc. Chem. Res. 2016, 49, 2690-2697.

(10) Ghosh, A.; Taylor, P. R. Curr. Opin. Chem. Biol. 2003, \%, 113-124.

(11) Pierloot, K. Mol. Phys. 2003, 101, 2083-2094.

(12) Harvey, J. N.; Poli, R.; Smith, K. M. Coord. Chem. Rev. 2003, 238, 347-361.

(13) Chen, H.; Lai, W.; Shaik, S. J. Phys. Chem. B 2011, 115, 1727-1742.

(14) Knowles, P. J.; Hampel, C.; Werner, H.-J. J. Chem. Phys. 1993, 99, 5219-5227.

(15) Watts, J. D.; Gauss, J.; Bartlett, R. J. J. Chem. Phys. 1993, 98, 8718-8733.

(16) Jiang, W.; DeYonker, N. J.; Determan, J. J.; Wilson, A. K. J. Phys. Chem. A 2011, $116,870-885$. 
(17) Bross, D. H.; Hill, J. G.; Werner, H.-J.; Peterson, K. A. J. Chem. Phys. 2013, 139, 094302.

(18) Radon, M. J. Chem. Theory Comput. 2014, 10, 2306-2321.

(19) Andersson, K.; Malmqvist, P.-Å.; Roos, B. O. J. Chem. Phys. 1992, 96, 1218-1226.

(20) Angeli, C.; Cimiraglia, R.; Evangelisti, S.; Leininger, T.; Malrieu, J.-P. J. Chem. Phys. 2001, 114, 10252-10264.

(21) Angeli, C.; Cimiraglia, R.; Malrieu, J.-P. J. Chem. Phys. 2002, 117, 9138-9153.

(22) Malmqvist, P. Å.; Pierloot, K.; Shahi, A. R. M.; Cramer, C. J.; Gagliardi, L. J. Chem. Phys. 2008, 128, 204109.

(23) White, S. R. Phys. Rev. Lett. 1992, 69, 2863.

(24) White, S. R. Phys. Rev. B 1993, 48, 10345.

(25) Kurashige, Y.; Yanai, T. J. Chem. Phys. 2011, 135, 094104.

(26) Kurashige, Y.; Chalupský, J.; Lan, T. N.; Yanai, T. J. Chem. Phys. 2014, 141, 174111.

(27) Wouters, S.; Van Speybroeck, V.; Van Neck, D. J. Chem. Phys. 2016, 145, 054120.

(28) Phung, Q. M.; Wouters, S.; Pierloot, K. J. Chem. Theory Comput. 2016, 12, 43524361.

(29) Nakatani, N.; Guo, S. J. Chem. Phys. 2017, 146, 094102.

(30) Guo, S.; Watson, M. A.; Hu, W.; Sun, Q.; Chan, G. K.-L. J. Chem. Theory Comput. 2016, 12, 1583-1591.

(31) Freitag, L.; Knecht, S.; Angeli, C.; Reiher, M. J. Chem. Theory Comput 2017, 13, $451-459$. 
(32) Radoń, M.; Pierloot, K. J. Phys. Chem. A 2008, 112, 11824-11832.

(33) Vancoillie, S.; Zhao, H.; Radoń, M.; Pierloot, K. J. Chem. Theory Comput. 2010, 6, $576-582$.

(34) Radoń, M.; Broclawik, E.; Pierloot, K. J. Chem. Theory Comput. 2011, 7, 898-908.

(35) Kepenekian, M.; Robert, V.; Guennic, B. L. J. Chem. Phys. 2009, 131, 114702.

(36) Lawson Daku, L. M.; Aquilante, F.; Robinson, T. W.; Hauser, A. J. Chem. Theory Comput. 2012, 8, 4216-4231.

(37) Pierloot, K.; Phung, Q. M.; Domingo Toro, A. J. Chem. Theory Comput. 2017, 13, $537-553$.

(38) Oláh, J.; Harvey, J. N. J. Phys. Chem. A 2009, 113, 7338-7345.

(39) Chen, H.; Lai, W.; Shaik, S. J. Phys. Chem. Lett. 2010, 1, 1533-1540.

(40) Jiang, W.; DeYonker, N. J.; Wilson, A. K. J. Chem. Theory Comput. 2012, 8, 460-468.

(41) Ahlrichs, R.; Bär, M.; Häser, M.; Horn, H.; Kölmel, C. Chem. Phys. Lett. 1989, 162, 165.

(42) Aquilante, F.; Autschbach, J.; Carlson, R. K.; Chibotaru, L. F.; Delcey, M. G.; De Vico, L.; Fdez. Galvn, I.; Ferr, N.; Frutos, L. M.; Gagliardi, L.; Garavelli, M.; Giussani, A.; Hoyer, C. E.; Li Manni, G.; Lischka, H.; Ma, D.; Malmqvist, P. .; Mller, T.; Nenov, A.; Olivucci, M.; Pedersen, T. B.; Peng, D.; Plasser, F.; Pritchard, B.; Reiher, M.; Rivalta, I.; Schapiro, I.; Segarra-Mart, J.; Stenrup, M.; Truhlar, D. G.; Ungur, L.; Valentini, A.; Vancoillie, S.; Veryazov, V.; Vysotskiy, V. P.; Weingart, O.; Zapata, F.; Lindh, R. J. Comput. Chem. 2016, 37, 506-541.

(43) Aquilante, F.; Malmqvist, P.-Å.; Pedersen, T. B.; Ghosh, A.; Roos, B. O. J. Chem. Theory Comput. 2008, 4, 694-702. 
(44) Ghigo, G.; Roos, B. O.; Malmqvist, P.-A. Chem. Phys. Lett. 2004, 396, 142-149.

(45) Forsberg, N.; Malmqvist, P.-A. Chem. Phys. Lett. 1997, 274, 196-204.

(46) Pierloot, K. In Computational Organometallic Chemistry; Cundari, T. R., Ed.; Marcel Dekker, Inc.: New York, 2001; pp 123-158.

(47) Pierloot, K. Int. J. Quantum Chem. 2011, 111, 3291-3301.

(48) Veryazov, V.; Malmqvist, P.; Roos, B. O. Int. J. Quantum Chem. 2011, 111, 33293338.

(49) Werner, H.-J.; Knowles, P. J.; Knizia, G.; Manby, F. R.; Schütz, M. WIREs Comput. Mol. Sci. 2012, 2, 242-253.

(50) Hess, B. A. Phys. Rev. A 1986, 33, 3742-3748.

(51) Reiher, M.; Wolf, A. J. Chem. Phys. 2004, 121, 2037-2047.

(52) Reiher, M.; Wolf, A. J. Chem. Phys. 2004, 121, 10945-10956.

(53) Kepp, K. P. Inorg. Chem. 2016, 55, 2717-2727.

(54) Balabanov, N. B.; Peterson, K. A. J. Chem. Phys. 2005, 123, 064107.

(55) Dunning Jr, T. H. J. Chem. Phys. 1989, 90, 1007-1023.

(56) Kendall, R. A.; Dunning Jr, T. H.; Harrison, R. J. J. Chem. Phys. 1992, 96, 6796-6806.

(57) Woon, D. E.; Dunning Jr, T. H. J. Chem. Phys. 1993, 98, 1358-1371.

(58) Jiang, W.; Wilson, A. K. J. Chem. Phys. 2011, 134, 034101.

(59) Halkier, A.; Helgaker, T.; Jørgensen, P.; Klopper, W.; Olsen, J. Chem. Phys. Lett. 1999, 302, 437-446.

(60) Helgaker, T.; Klopper, W.; Koch, H.; Noga, J. J. Chem. Phys. 1997, 106, 9639-9646. 
(61) Vancoillie, S.; Zhao, H.; Tran, V. T.; Hendrickx, M. F. A.; Pierloot, K. J. Chem. Theory Comput. 2011, 7, 3961-3977.

(62) Collman, J. P.; Hoard, J.; Kim, N.; Lang, G.; Reed, C. A. J. Am. Chem. Soc. 1975, 97, 2676-2681.

(63) Kitagawa, T.; Teraoka, J. Chem. Phys. Lett. 1979, 63, 443-446.

(64) Dolphin, D.; Sams, J. R.; Tsin, T. B.; Wong, K. L. J. Am. Chem. Soc. 1976, 98, 6970-6975.

(65) Sligar, S. G. Biochemistry 1976, 15, 5399-5406.

(66) Munro, O. Q.; de Wet, M.; Pollak, H.; van Wyk, J.; Marques, H. M. J. Chem. Soc., Faraday Trans 1998, 94, 1743-1752.

(67) Howes, B. D.; Feis, A.; Indiani, C.; Marzocchi, M. P.; Smulevich, G. J. Biol. Inorg. Chem. 2000, 5, 227-235. 


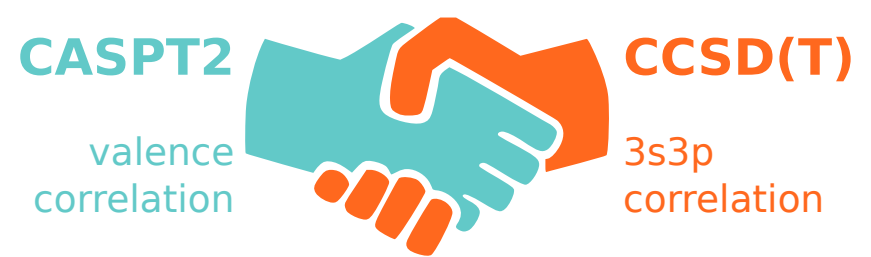

Table of Contents - Graphic 